\title{
A narrative review of changes in microvascular permeability after burn
}

\author{
Yunfei Chi", Xiangyu Liu", Jiake Chai \\ Burn Institute, The Fourth Medical Center of the PLA General Hospital, Beijing, China \\ Contributions: (I) Conception and design: Y Chi; (II) Administrative support: X Liu; (III) Provision of study materials or patients: Y Chi; (IV) \\ Collection and assembly of data: Y Chi, X Liu; (V) Data analysis and interpretation: Y Chi, J Chai; (VI) Manuscript writing: All authors; (VII) Final \\ approval of manuscript: All authors. \\ "These two authors contribute equally to this work. \\ Correspondence to: Jiake Chai. Burn Institute, The Fourth Medical Center of the PLA General Hospital, 51 Fu Cheng Road, Beijing 100048, China. \\ Email: cjk304@126.com.
}

\begin{abstract}
Objective: We aimed to review and discuss some of the latest research results related to post-burn pathophysiological changes and provide some clues for future study.

Background: Burns are one of the most common and serious traumas and consist of a series of pathophysiological changes of thermal injury. Accompanied by thermal damage to skin and soft tissues, inflammatory mediators are released in large quantities. Changes in histamine, bradykinin, and cytokines such as vascular endothelial growth factor (VEGF), metabolic factors such as adenosine triphosphate (ATP), and activated neutrophils all affect the body's vascular permeability.

Methods: We searched articles with subject words "microvascular permeability", "burn" "endothelium", and "endothelial barrier" in PubMed in English published from the beginning of database to Dec, 2020.

Conclusions: The essence of burn shock is the rapid and extensive fluid transfer in burn and non-burn tissue. After severe burns, the local and systemic vascular permeability increase, causing intravascular fluid extravasation, leading to a progressive decrease in effective circulation volume, an increase in systemic vascular resistance, a decrease in cardiac output, peripheral tissue edema, multiple organ failure, and even death. There are many cells, tissues, mediators and structures involved in the pathophysiological process of the damage to vascular permeability. Ulinastatin is a promising agent for this problem.
\end{abstract}

Keywords: Burns; capillaries; permeability; endothelium

Submitted Jan 15, 2021. Accepted for publication Apr 17, 2021.

doi: 10.21037/atm-21-1267

View this article at: http://dx.doi.org/10.21037/atm-21-1267

\section{Introduction}

Burns are one of the most common and serious injuries. Among all serious accidents, the incidence of burns is second only to car accident injuries. Although the incidence of burns has been declining in recent years, severe burns still pose a huge challenge to medical systems around the world, especially in developing countries. According to statistics, more than two-thirds of severe burns occur in the Asia-Pacific region (1). With the continuous improvement of medical service worldwide, the success rate of burn treatment has continued to rise, but statistics show that burn patients admitted to hospital still have a mortality rate of $3 \%$ to $8 \%$ (2). A statistical report on burn patients in the United States published by Zavlin et al. in 2018 showed that about $3.3 \%$ of burn patients did not survive, with $52 \%$ dying within 7 days after admission (3). Another study suggested that among patients who died of burns, $58 \%$ of deaths occurred within 72 hours after injury (4). Both results remind us that the early stage of burns is a critical period for patient survival. The study of pathophysiological changes and key treatment methods in the shock stage of 
burns is still an important task for scholars and clinicians to undertake.

Burns are a series of pathophysiological changes that start from heat injury. Accompanied by heat damage to the skin and soft tissues, a large amount of inflammatory mediators is released into circulation. Changes in histamine, bradykinin, and platelet-activating factor (PAF), cytokines such as vascular endothelial growth factor (VEGF), metabolic factors such as ATP and activated neutrophils all affect the body's vascular permeability (5). The essence of burn shock is the rapid and extensive fluid transfer in burn and non-burn tissues (6). After severe burns, the local and systemic vascular permeability increase, causing intravascular fluid extravasation, leading to a progressive decrease in effective circulation volume, an increase in systemic vascular resistance, a decrease in cardiac output, peripheral tissue edema, multiple organ failure, and even death $(7,8)$. The increase in vascular permeability is characterized as a significant change in the permeability of capillaries and post-capillary venules. In other words, the normal physiological barrier function of endothelial cells (ECs) is destroyed (9). In recent years, a large number of studies have been conducted on the pathophysiological mechanism, molecular mechanism, and targeted therapy of microvascular permeability changes (9-16) since microvascular permeability plays an important role in the process of material exchange. This article will review and discuss some of the research results related to post-burn pathophysiological changes. We present the following article in accordance with the Narrative Review reporting checklist (available at http://dx.doi. org/10.21037/atm-21-1267).

\section{Methods}

We searched articles with subject words "microvascular permeability", "burn" "endothelium", and "endothelial barrier" in PubMed in English published from the beginning of database to Dec, 2020.

\section{Histological basis of microvascular endothelial barrier}

The microvascular endothelial barrier is formed and maintained by the microvascular wall, which is composed of ECs, endothelial glycocalyx (EG), basement membrane (BM), and some auxiliary cells, which together constitute a single, tight, selective barrier (10).

\section{Microvascular ECs}

The histological basis for changes in microvascular permeability is the change in the morphology (cellular edema, flat to round), function, and connection of vascular ECs. The vascular EC monolayer is distributed in the inner lining of the visceral layer of the blood vessel wall, which is the critical surface between the blood vessel wall and the fluid in the blood vessel. Vascular ECs form a semipermeable diffusion barrier between blood and tissues, actively participate in the blood-tissue exchange of plasma, proteins, and cells, and simultaneously function as sensors and effectors. Vascular ECs regulate various functions of blood vessels, including vascular smooth muscle tension, host defense response, angiogenesis, and tissue fluid hemostasis. Under the action of histamine, bradykinin, PAF, VEGF, and other inflammatory mediators or cytokines, the structural conformation of ECs changes to increase the permeability of the vascular endothelial barrier (10). The increased permeability of the vascular endothelial barrier leads to extravasation of blood components in the blood vessels, accumulation of albumin and plasma components in the interstitium, and the swelling or edema of interstitial tissues which is difficult to control. This further aggravates the body's inflammatory response and promotes the high permeability of microvasculature, leading to additional tissue damage and organ failure (11). Therefore, microvascular ECs are essential for maintaining circulatory homeostasis and the physiological functions of different organs (12).

\section{Endothelial surface layer and endothelial glycocalyx}

The endothelial surface layer (ESL) is the cell membrane surface on the lumen side of ECs, and it is an important part of the microvascular endothelial barrier. Its penetration is closely regulated by many factors, including molecular size, charge, and structure (13). In previous studies of microvascular inflammation, it has been found that damage to the ESL may be the first sign of microvascular endothelial dysfunction (14). The ESL affects mechanical transduction, vascular permeability, rheology, thrombosis, and leukocyte adhesion. It establishes a barrier between ECs, blood, and neighboring cells, with the endothelial glycocalyx being an important part of the ESL in this regard (15).

Glycocalyx is a negatively charged surface coating. The apparent thickness varies from 20 to $3,000 \mathrm{~nm}$, and the thickness varies with different tissues and different 
staining methods (16). Glycocalyx is a composite layer composed of membrane-bound proteoglycans, sialic acidcontaining glycoproteins, glycolipids, and adsorbed plasma proteins (17), which communicate between and within cells and maintain tissue homeostasis (18). The negative charge of the glycocalyx makes it have a repulsive effect on red blood cells, which suggests that glycocalyx can regulate oxygen transport in a charge-dependent manner (19) and can play a role in protecting the endothelium from leukocyte adhesion. The glycocalyx may also perform the function of "gating" macromolecules of different charges into specific areas on the surface of ECs, and the combination of macromolecules may also change the structure and charge distribution of the glycocalyx, thereby affecting the penetration of plasma proteins (20). The importance of glycocalyx in maintaining endothelial permeability by selectively repelling plasma protein has been demonstrated by research. Arisaka et al. have shown that endothelial glycocalyx can also function as a fluid shear stress sensor (21). In addition, the heparin sulfate and hyaluronic acid components of the glycocalyx have been found to play an important role in regulating endothelial nitric oxide (NO) production (22) and stimulating cytoskeletal reorganization (23).

Under pathophysiological conditions, such as the destruction of glycocalyx by proteolysis activated by tumor necrosis factor (24), glycocalyx degradation factors, including reactive oxygen and nitrogen substances, matrix metalloproteinases, heparinase, and sialidase, are produced, which destroy the endothelial surface layer, thereby impairing endothelial function. This in in turn leads to increased capillary permeability, leukocyte-endothelial interaction, thrombosis, and vascular inflammation, the latter of which further promotes the destruction of glycocalyx (25). It can be seen that the research on the endothelial surface layer and endothelial glycocalyx may be critical for exploring new therapeutic targets for microvascular permeability. When the composition or structure of the glycocalyx is destroyed, or its negative charge is neutralized, the permeability of the capillaries increases. Research by Rahbar et al. has shown that when the glycocalyx components of the vascular endothelium of trauma patients fall off and the colloidal osmotic pressure (COP) in plasma decreases, the shedding of proteoglycan-1 and hyaluronic acid increases significantly, and the plasma colloidal osmotic decreases. This correlates with glycocalyx degradation and thrombin loss after trauma, which affects permeability and coagulation function (26). Findings from Zhao et al. show that hydroxyethyl starch $(130 / 0.4)$ has a protective effect on the vascular barrier function after hemorrhagic shock, and its mechanism is mainly related to the downregulation of heparinase, hyaluronidase, and neuraminic acid by hydroxyethyl starch. The expression of enzymes is related to the protective effect of endothelial glycocalyx and intercellular junction protein (27). In one study, Jacob et al. injected physiological concentrations of type $A$, type $B$, and type $C$ natriuretic peptides into the coronary arteries, and found that there were eluted glycocalyx components (proteoglycan-1 and heparan sulfate) in the coronary veins, the functional vascular barrier ability had been reduced, and that the formation of leakage and the exudation of colloidal hydroxyethyl starch had increased significantly. Phenanthroline, a nonspecific inhibitor of matrix metalloproteinases, can reduce glycocalyx shedding induced by A-type natriuretic peptide (28). This suggests that the inhibition of metalloproteinases may become the basis for future treatment options.

\section{Basement membrane and extracellular matrix (ECM)}

The basement membrane of vascular ECs is a special ECM, which serves as a support material for vascular ECs and also separates vascular ECs from the underlying tissues (29). The thickness of the vascular basement membrane is about 20-200 nm, and the basic components of the ECM are composed of type IV collagen, fibronectin, dentin, laminin, chondroitin sulfate, heparin sulfate, basement membrane glycan, and polyligand glycan (30). In addition, the ECM also contains stromal cell proteins (or matrix-associated proteins), thrombin-sensitive protein (thrombospondin, TSP) and secreted protein acidic and rich in cysteine (SPARC) (31). Among the many components, type IV collagen is the most important and exists in the form of covalent cross-linking, while other components of the basement membrane are attached to the network structure of collagen IV in a noncovalent cross-linked manner. During the formation of basement membrane, ECs first secrete laminin polymer and combine with $\beta 1$-integrin (32). Type IV collagen polymer then interacts with laminin polymer in the extracellular space to form a scaffold, and other ECM proteins are assembled on the scaffold to produce a basement membrane with abnormally high elasticity and tensile strength (31).

In recent years, many studies have been carried out on the changes in the ECM under pathological conditions that induce the increase of microvascular permeability. Studies by Mammoto et al. suggest that changes in ECM 
mechanics affect pulmonary vascular permeability, and that lysyl oxidase (LOX)-mediated changes in ECM can regulate pulmonary vascular permeability. They believe that LOX and the resulting changes in ECM structure may be new therapeutic targets for abnormal vascular permeability (33). Meanwhile, Qiao et al. evaluated the effects of albumin and Ricinus communis agglutinin (RCA) on the monolayer conductivity of bovine lung microvascular ECs. Further, studies have found that the treatment of ECs with castor bean can reduce the transendothelial permeability of albumin by enhancing the ECM barrier. The reason for this is that the lectin modification of the ECM reduces the permeability of the ECM to albumin (34). Research by Hendel et al. found that granzyme B can increase vascular permeability and acts on the ECM to release the ECMisolated VEGF through proteolysis, leading to VEGF receptor 2 (VEGFR2) activation and increased vascular permeability in vivo (35). Hahn et al. reported a novel matrix factor, the collagen-derived matrix factor acetylated prolineglycine-proline (Na-PGP), which is derived from ECM and which regulates cells bypass permeability in the process of inflammatory diseases. This result indicates that the ligand has a targeting effect in various diseases characterized by excessive matrix conversion and vascular leakage (36). In addition, studies have shown that fibronectin in the ECM protects the vascular endothelial barrier by maintaining the integrity of the ECM. The release of fibronectin from the ECM also increases the permeability of the endothelium to albumin by $2-3$ times. The reincorporation of plasma fibronectin into the ECM can prevent the increase in the permeability of the endothelial monolayer (37). Studies on hyaluronidase degradation of hyaluronic acid to increase the permeability of the vascular endothelial monolayer have shown that the degraded hyaluronic acid leads to an increase in the conductivity of the ECM, thereby destroying the barrier function of the endothelium to fluid (38). The above-mentioned studies related to basement membrane and ECM together support the important role of ECM in regulating endothelial barrier function.

\section{Microvascular endothelial transport pathways}

We know that the most extensive material exchange in the human body is the exchange of plasma components across the endothelium of the vascular system. Continuous ECs and windowed ECs can carry out rapid and extensive two-way exchange of large and small molecules for the entire circulatory system (39). The microvascular exchange system, composed of capillaries and venules after capillaries, is the most important site for exchange, as it has an exceedingly large surface area (about 600 square meters) (40). In the vascular bed of the circulatory system, the exchange or transportation of substances through the vascular endothelium occurs through two pathway types: transcellular pathways and paracellular pathways.

\section{Transcellular pathway}

The transcellular pathway is believed be responsible for the normal and physiological transendothelial transport of macromolecules. The transportation of many macromolecular substances (albumin, immunoglobulin, insulin, plasma ceruloplasmin, low-density lipoprotein, nonsteroidal hormones) and drugs have been confirmed to be conducted through this method (41). The active transport of macromolecules such as albumin is mainly completed by the transcellular transport mediated by caveolae and vesiculo-vacuolar organelles $(42,43)$. The caveolae occupy a specialized small invagination area on the surface of the plasma membrane, which is widely present in various types of cells, and is very rich in microvascular ECs (44). In addition to mediating the transport of macromolecules, caveolae also play an important role in lipid homeostasis and signal transduction (45). The current research has revealed that the protein components of the caveolae can be divided into core structural components and key auxiliary proteins. The core structural components include caveolin-1 (CAV1) and CAV3 (46). Mammals have three caveolin genes, CAV1, CAV2, and CAV3. CAV1 is mainly expressed in non-muscle cells, and CAV3 is mainly expressed in muscle cells. The genetic deletion of these two genes will lead to the loss of caveolae in their respective tissues $(47,48)$. Research on CAV1 gene knockout mice (Cav-1-/-) found that CAV-1, a key structure and signal protein of the caveolae, to be missing, which led to the dysfunction of vascular ECs transporting albumin through the caveolae (49). The four different domains of CAV1 currently known are the $\mathrm{N}$-terminal domain (residues 1-81 in human CAV1), the scaffold domain (residues 82-102 in CAV1), the intramembrane domain (residues 103-133), and C-terminal (residues 134-178 in CAV1) (50). The precise role of these four domains has not yet been fully investigated, and thus remains a primary research direction in determining the function of caveolae. CAV1 is synthesized in the endoplasmic reticulum of vascular ECs. After forming oligomers, these oligomers pass through 
the Golgi complex and reach the cell surface through a cholesterol-dependent process. Lipid composition, accessory proteins, and the structure of the caveolinenriched area on the surface may all participate in the binding of caveolae to ensure that caveolae are only formed on the cell surface (51). The caveolae can sprout from the plasma membrane in a manner similar to vesicles wrapped by reticulum to form endocytic vesicles. The caveolae pass through the cytoplasm to reach the basolateral surface, where they release their contents through exocytosis, completing the process of macromolecule transport (52).

In pathological conditions such as burns, trauma, and acute lung injury, inflammation is initiated, neutrophils are activated (polymorphonuclear neutrophils, PMNs), vascular permeability increases, and edema is formed. $\mathrm{Hu}$ et al. used a monoclonal antibody blocked by intercellular adhesion molecule (ICAM)-1 to block ICAM-1-mediated PMN binding to ECs and inhibit the Src phosphoric acid of CAV-1. This also increased the permeability of the endothelium, which indicates that the high permeability of pulmonary blood vessels caused by the activation of neutrophils adhering to the vessel wall depends to a large extent on the CAV-1 signal and the increase of cavernmediated cells in transshipment (53). It can be seen that when developing treatment interventions for PMNmediated inflammatory diseases, it is important to consider the role of transendothelial vesicle permeability pathways that promote edema formation. We know that nitric oxide (NO) can actively regulate the function of blood vessels and ECs. Endothelial nitric oxide (eNOS) is the main source of vascular $\mathrm{NO}$, and the abnormal regulation of eNOS activity is related to a series of abnormal vascular endothelial functions (54). Studies have found that CAV1 binds to eNOS and inhibits eNOS activity by limiting the accessibility of eNOS to calmodulin (CaM) (55). More recent studies by Trane et al. revealed that phenylalanine 92 plays a key role in CAV-1's inhibitory effect on eNOS and the CAV [90-99] peptide of F92A in an eNOS and CAV-1dependent manner. Delivery can increase the bioavailability of NO (56). These results provide the possibility to study the inhibitory effect of CAV-1 on eNOS without interfering with other effects of endogenous CAV-1. Zhang et al. used models of changes in pulmonary microvascular permeability after cardiopulmonary bypass and found that the Src kinase pathway increases pulmonary microvascular permeability, which is related to the activation of CAV1 and vascular endothelial cadherin (VE-cadherin) (57). Some scholars have tried to use lipopolysaccharides to induce CAV-1 phosphorylation, which leads to an increase in transcellular permeability. This has been verified in the study of rat pulmonary microvascular ECs and represents a new strategy to treat inflammatory diseases associated with increased microvascular permeability (58). In addition, the 2020 study by Jones et al. suggested that the loss of plasmalemmal vesicle-associated protein (PV1) in vascular ECs could increase the permeability of fluid and protein in the pulmonary blood vessels, guide the uptake of the tracer albumin, and promote the accumulation of albumin gold in the fossa ball to induce fossa swelling. After endothelial-specific PV1 deletion, these changes occur without disrupting the endothelial connection. It has been proven that the key function of PV1 is to regulate lung endothelial permeability by restricting plasma proteins (such as albumin) from entering the cavities and prohibiting their transport through the endothelial barrier (59). This provides a new idea for interfering with the function of the fovea and affecting the vascular endothelial barrier.

\section{Paracellular patbway}

The paracellular pathway mediates the transport of water and solutes from ions to macromolecules (60), which is carried out through the connection gap between ECs. The gap contains protein fiber matrix, which acts as a molecular sieve, which can exclude solutes according to size or charge. The important effector of the pathway is the interendothelial junctions (IEJ) (61). The restrictive properties of the undisturbed endothelial barrier are mainly restricted by the closed interendothelial connection. Interendothelial connexin and integrin receptors provide adhesion to the EC monolayer through their connection with the actin cytoskeleton to resist the separation of cells from the matrix and adjacent cells (62). Studies have found that the proteins bound to the IEJ also interact with the ECM junction proteins. The effects of the IEJ and the ECM components on the endothelial barrier function may be additive (63). IEJs are ECs connected to each other through a complex set of junction proteins, including adhesion junctions (AJs), tight junctions (TJs) and gap junctions (GJs) (64). Among them, AJs and TJs are most apparent in mediating cell adhesion and barrier properties. They form a zipper-like structure along the cell boundary through transmembrane affinity adhesion.

AJs are identified as tightly attached areas of the EC membrane in the ultrastructure, and are of fundamental importance in regulating the endothelial barrier function (65). 
Endothelial AJ contains vascular endothelial cell-cadherin (VE-cadherin) as the main structural protein, which mediates homophilic binding and adhesion of adjacent cells in a calcium-dependent manner. VE-cadherin is necessary for the proper assembly of AJs and the development of normal endothelial barrier function (66). The application of VE-cadherin antibody can destroy the homotypic binding of cadherin protein, which contributes to the increase in the permeability of the microvascular endothelium to macromolecules (67). In addition, VE-cadherin can also regulate AJ permeability by regulating the GTP binding and GTP hydrolysis of Cdc42, Rac and RhoA. The final result of the activation state of these Rho GTPases may control the actin polymerization at the junction, thereby fine-tuning the connection permeability (68). In addition, studies by scholars such as Iyer have confirmed that p120-catenin combined with VE-cadherin becomes a negative regulator of RhoA function, thereby helping to downregulate endothelial permeability (69).

TJs are the fusion points of the lateral membrane outer lobes between adjacent ECs, accounting for $20 \%$ of the total number of EC junction complexes (65). The TJ tissues in ECs vary according to their location in the circulatory system. The arterial segment has 2-7 highly connected and well-developed ECs, while the vein segment has 1 to 3 discontinuous ECs (70). The role of TJs in the barrier of paracellular pathways has been continuously proposed, but has still not been fully elucidated. Among the TJs, occludin, zona atresia protein $1, \mathrm{ZO}-\mathrm{I}$, and junctional adhesion molecule (JAM) all play important roles. The occludin protein is the first intact membrane protein located in TJs and plays an auxiliary role in the assembly of TJs (71). The COOH end of occludin binds to the $\mathrm{ZO}-1$ protein in the cytoplasm, and the $\mathrm{ZO}-1$ protein is connected to the cytoskeleton of $\alpha$-catenin, spectrin, and actin. Occludin is linked to the cytoskeleton of ZO-1 and actin, with their interactions stabilizing TJ, demonstrating the important role of occludin in regulating the structure of TJs (72). JAM, the link adhesion molecule, belongs to the immunoglobulin superfamily and is a one-way membrane protein. Studies have found that blocking antibodies or recombinant soluble forms of JAM-1 block the reannealing of TJs in epithelial cells. Therefore, the ability of JAMs to pass tight connection acts to regulate the integrity of the endothelial barrier (73).

Under the pathophysiological conditions of acute inflammation such as burns and trauma, the increased permeability of microvascular endothelium to plasma proteins is believed to be largely due to the opening of paracellular pathways (74). The paracellular pathway is also the migration path of many pathogens, white blood cells, and even metastatic tumor cells (75). Inflammatory mediators, thrombin, bradykinin, histamine, PAF, VEGF and other agonists bind to their receptors and destroy the interendothelial connection and integrin-ECM complex, thereby opening the connection barrier of the vascular endothelium (76). Under physiological conditions, vascular ECs maintain their characteristic flat shape through the centrifugal tension generated by the microtubule pillars, focal adhesions and interendothelial connections between cells (77). In a pathological state, based on agonist stimulation, the formation of actin stress fibers increases, which makes microtubules unstable and induces RhoA activation, which in turn leads to increased actin stress fiber formation and endothelial contraction, and causes ECs to be round (78). Changes in the shape of ECs lead to the formation of EC gaps and changes in the barrier function of paracellular pathways. This is one of the important determinants of the increase in microvascular endothelial permeability under pathological conditions (79). The permeability of the paracellular pathway increases, and albumin and other plasma proteins penetrate into the interstitial space. Many mediators with increased permeability contribute to this mechanism to further increase the permeability of the vascular endothelium. The use of ethylenediaminetetraacetic acid (EDTA), antiVE-cadherin blocking antibody, and other interventions that directly affect the integrity of the IEJ have been examined using experiments on cultured cells and intact blood vessels, which have further confirmed the above mechanism (80). Recent studies have found that high mobility group protein B1 (HMGB1) can induce transcellular filamentous actin rearrangement and form stress fibers, causing VE-cadherin fragments to localize on the edge of ECs. The gap widens and the permeability increases (81). Research by Mohammad etc. indicates that the transient receptor potential channel 1 (TRPC1) mediates the entry of $\mathrm{Ca}^{2+}$ and destroys the adhesion connection, while other research shows that TRPC1 inhibits the activity of sphingosine kinase 1 (SPHK1), destabilizing the endothelium cell barrier (82).

\section{Burn-related agonists mediate increased microvascular permeability}

Severe burns are caused and are characterized by heat injury, and superimpose the acute inflammatory process following heat injury (83). The short-term sharp rise of body surface 
temperature causes rapid local response of regional blood vessels, in an attempt to dissipate heat through vasodilation. Local temperature increase and necrotic tissue stimulation further trigger local and systemic inflammatory reactions caused by the release of inflammatory mediators, which is followed by a cascade reaction (84). The increasing systemic microvascular permeability, systemic leakage of plasma proteins, and subsequent interstitial tissue edema and organ dysfunction are the typical pathophysiological processes of hypovolemic shock after burns $(85,86)$. There are many factors that influence the accumulation of plasma components and body fluids after burns, including increased filtration pressure and fluid absorption, impaired lymphatic clearance, and general cell membrane damage (87), but the microvascular endothelial barrier dysfunction is the main factors of development of burn-associated edema (88). A variety of endothelial permeability inflammatory mediators are involved in the complex mechanism of microvascular endothelial barrier dysfunction after burns, including histamine, bradykinin, cytokines, leukocyte adhesion, free radicals, proteases, and other mediators (89). This complicated mechanism of action and signaling pathway has not yet been fully elucidated, but ongoing research is continually clarifying this process. Below we will discuss several major inflammatory mediators that appear after burns and the related research progress in recent years.

\section{Histamine}

Histamine is produced by histidine under the action of decarboxylase and is stored in mast cells of various tissues, such as then skin, lungs and intestinal mucosa. When body tissues are burned, histamine is released from mast cells, act on ECs, fibroblasts, and smooth muscle cell tissues, exert a strong vasodilator effect, and can significantly increase the permeability of microvascular endothelium (90). Currently known receptors that bind to histamine are the four subtypes of $\mathrm{G}$ protein-coupled receptors $(\mathrm{H} 1, \mathrm{H} 2, \mathrm{H} 3$, and H4) (91). Among them, $\mathrm{H} 1$ and $\mathrm{H} 2$ exist in large vessels and microvascular ECs, and $\mathrm{H} 1$ is considered to be the most important subtype related to vascular permeability (92). After the body is burned, histamine is released in large quantities, binds to $\mathrm{H} 1 \mathrm{~s}$ of vascular ECs, activates phospholipase C- $\beta$ (PLC- $\beta$ ), and increases the intracellular calcium ion concentration, thereby increasing the myosin light chain kinase (MLCK) activity (93). In turn, MLCK increases the phosphorylation of myosin light chain (MLC) and triggers actin-myosin contraction (94). In addition, histamine can also rely on RhoA and Rac to induce the formation of actin stress fibers (65). At the connection level, histamine can cause the serine phosphorylation of $\beta$-catenin and $\mathrm{VE}$-cadherin, which transfers these $\mathrm{AJ}$ proteins from the cell membrane to the cytoplasm, leading to adhesion connection's phosphorylation of TJ components, resulting in the destruction of the junction between ECs (95). After burns, histamine acts on the connections between ECs in multiple ways, which can make the connections between the vascular endothelial cells form gaps ranging in size from 100 to $400 \mathrm{~nm}$ (96), increasing the permeability of microvascular ECs in a short time and causing extravasation of plasma components.

In view of the role and mechanism of histamine on microvascular permeability, the exploration of targeted research is also constantly being conducted. Studies by Boykin et al. have found that cold water treatment can significantly reduce the histamine release of burned ears, and the use of $\mathrm{H} 2$ antagonist cimetidine before injury can reduce distal edema (97). Reynoso et al. focused on the long subtype MLCK-210, which was determined to be the subtype mainly expressed in vascular ECs. The study found that in wild-type mice, burns caused albumin flux to increase by 2 times and hydraulic conductivity of mesenteric microcirculation to increase by 4 times; meanwhile, mice lacking MLCK-210 had reduced albumin hyperpermeability and an improved survival rate (98). Chen et al. found that atrial natriuretic peptide (ANP) could reduce the inflammation of histamine through endothelial GC-A/ cGMP/cGKI signal transduction and phosphorylation of TRPC6 channels. Furthermore, sildenafil improved the system's endothelial barrier function by enhancing the endothelial effect of endogenous ANP. This new regulatory approach has considerable therapeutic potential (99). A study by Si et al. in 2020 found that calcium releaseactivated channels (CRAC) channels play an important role in mediating $\left(\mathrm{Ca}^{2+}\right)$ signaling and downstream endothelial barriers and inflammation induced by histamine. Targeting CRAC can alleviate the high p vascular endothelial permeability and lymphatic inflammatory disease induced by histamine (100). The above-mentioned studies of molecules or signal pathways provide the possibility of finding therapeutic targets for the microvascular endothelial barrier dysfunction caused by histamine after burns.

\section{Bradykinin}

After skin and soft tissue burns, the serine protease family 
(kallikrein) produces bradykinin at the tissue injury site. Bradykinin is a nonapeptide that has an inflammatory effect and vasoactivity (101). Bradykinin has the effect of increasing the permeability of microvascular ECs, as confirmed by studies of monolayer EC culture and intact microvessels $(102,103)$. Currently known bradykinin receptors include three receptor subtypes B1, B2, and B3. The three receptors have different affinities for kinin. The relative effect of bradykinin receptor antagonists to the three receptors is also different (104). In microvascular ECs, there are B1 receptors and $\mathrm{B} 2$ receptors. B1 bradykinin receptor $(\mathrm{B} 1 \mathrm{R})$ is a $\mathrm{G}$ protein-coupled receptor with 7 transmembrane domains. The structural activity of B1R depends on transmembrane and intracellular epitopes. B1 receptor is expressed after injury or inflammation, it has the characteristics of resisting desensitization and internalization, and the activation reaction time limit is long (105). B2 receptor is structurally expressed and has a short activation time. Bradykinin can promote the recruitment and isolation of occupied receptors and receptor-coupled $G$ protein alpha subunits Galphaq and Galphai in the caveolae (106). Bradykinin activates the $\mathrm{B} 1$ and $\mathrm{B} 2$ receptors of microvascular ECs, increases intracellular $\mathrm{Ca}^{2+}$ leading to the ECs' production of prostaglandins and $\mathrm{NO}$, thus increases the permeability of the endothelial junction (107).

With consideration to the pathophysiological effects of bradykinin, many studies on bradykinin receptor antagonists have been carried out in recent years, with the main aim being treating diseases caused by excessive production of kinin. These diseases include rheumatoid arthritis and intestinal tract inflammation, asthma, rhinitis, sore throat, and allergic reactions (108). In previous studies, Yong et al. discussed the role of neutral endopeptidase and angiotensinconverting enzyme, which are widely distributed in microcirculation; they found that, when induced by bradykinin, these agonists could increase the blood vessel permeability of the hamster cheek pouch. Endopeptidase and angiotensin-converting enzyme each play an important role in the regulation of bradykinin-induced increase in vascular permeability in vivo (109). Cicardi et al. used icatibant, a selective bradykinin B2 receptor antagonist, to treat patients with hereditary angioedema. The study found that compared with tranexamic acid, icatibant can significantly reduce the time to relieve symptoms of angioedema (110). Bartal et al. reported on the application of icatibant in the treatment of angiotensin-converting enzyme (ACE) inhibitor-induced laryngeal angioedema, considering the close relationship between bradykinin B2 receptor and angioedema, they proposed an emergency plan for the careful use of icatibant for life-threatening angioedema (111). There are few studies on antagonizing bradykinin for treatment of vascular permeability changes after burns, but the research on the role of bradykinin receptor antagonists in other vascular diseases have provided us with a wealth of reference.

\section{Tumor necrosis factor- $\alpha(T N F-\alpha)$}

TNF- $\alpha$ is one of the most common inflammatory cytokines. After the body is burned, TNF- $\alpha$ is released by activated monocytes and macrophages isolated in the microcirculation (112). TNF- $\alpha$ has a wide range of effects and is involved in mediating the physiological changes of various burn cases. Studies have found that TNF- $\alpha$ may participate in post-burn immunosuppression by inducing thymocyte apoptosis (113). TNF- $\alpha$ is closely related to postburn infection, and the ratio of TNF- $\alpha$ /interleukin (IL-10) is related to burn severity and repeated infections (114). Another study reported that the application of antiTNF- $\alpha$ antibody can significantly improve the trabecular bone volume after burns, suggesting that TNF- $\alpha$ is also involved in bone loss after severe burns (115). TNF- $\alpha$ is also involved in intestinal mucosal cell apoptosis after burns, and the interaction of TNF- $\alpha$ and TNF receptor (TNFR) activates intestinal mucosal cell apoptosis (116). In the cardiovascular system, the secretion of cardiomyocytes and circulating TNF- $\alpha$ after burns cooperate with other inflammatory cytokines to produce burn-mediated systolic dysfunction (117). The effect of TNF- $\alpha$ on the microvascular system can upregulate intercellular adhesion molecule-1 (ICAM-1) and E-selectin (118), and promote the adhesion of neutrophils to endothelium and the production of reactive oxygen species (ROS) and increases the permeability of microvascular ECs (119). After burns, TNF- $\alpha$ can increase the permeability of microvascular ECs by activating the RhoA signaling pathway through protein kinase C- $\alpha$ (120). TNF- $\alpha$ also increases microvascular endothelial permeability by mediating microtubule rearrangement and adhesion connections activated by p38MAPK (121). In addition, studies have confirmed that TNF- $\alpha$ can increase microvascular endothelial permeability by affecting integrin-mediated adhesion of ECs to the fibronectin matrix (122). In the study of sepsis, it was found that TNF- $\alpha$ can induce the expression of TRPC1, promote $\mathrm{Ca}^{2+}$ influx, and affect endothelial permeability (123). In short, after severe burns, a large amount of TNF- $\alpha$ in 
the blood increases the permeability of the microvascular endothelium through multiple channels, leading to extravasation of plasma components and interstitial edema.

For many years, research aimed at blocking the effect of TNF- $\alpha$ has been ongoing. Duansak et al. studied the effects of aloe on the microcirculation and TNF- $\alpha$ levels in burned rats, and found that aloe can decrease the TNF- $\alpha$ level after burns and reduce the adhesion of white blood cells (124). Based on TNF- $\alpha$ knockout (TNF- $\alpha \mathrm{KO}$ ) and caspase- 3 gene knockout in a mouse model of severe burn, Zhao et al. used simvastatin to observe changes in liver cell apoptosis after burns. The results suggest that simvastatin can inhibit the expression of TNF- $\alpha /$ caspase- 3 pathway and reduce hepatocyte apoptosis in burned mice (125). Later, Zhao et al. once again explored the effect of simvastatin on skin cell apoptosis in severely burned mice. Their study found that simvastatin can downregulate TNF- $\alpha / \mathrm{NF}-\kappa \mathrm{B}$ expression, thereby reducing spleen cell apoptosis after burns (126). Research by Friedrich et al. suggested that the combination of anti-TNF- $\alpha$ monoclonal antibody and high molecular weight hyaluronic acid (HA) can reduce secondary necrosis in rats with deep second-degree burns. The results indicate that this combination can adjust the residence time of the therapeutic protein and is an effective strategy to adjust the inflammatory response associated with acute injury (127). Although the above studies have limited content in blocking the increase in TNF- $\alpha$-mediated microvascular permeability, studies on antagonizing and blocking TNF- $\alpha$ pathway can still provide new ideas for the study of microvascular permeability.

\section{Oxidants}

After body burns occur, systemic edema appears and continues to aggravate. Oxidants are involved in this process from the beginning (128) when macrophages and neutrophils release a large amount of ROS, including hydrogen peroxide $\mathrm{H}_{2} \mathrm{O}_{2}$, superoxide anion $\mathrm{O}^{2-}$, and hydroxyl radical$\mathrm{OH}$, peroxide (129). A number of studies have revealed that hydrogen peroxide, superoxide anions, and hydroxyl free radicals can rely on neutrophil adhesion to interact with microvascular ECs and damage vascular ECs (130). Neutrophils undergo a series of dynamic changes after burns, adhere to venous ECs, and then migrate and chemotaxis through ECs to the stimulation site (131), which will cause mechanical damage to ECs in the process. Oxidants, along with the adhesion of neutrophils, play a role in destroying the vascular endothelial barrier; meanwhile, the exudation of plasma components and proteins also occurs (132). In a complex process of endothelial barrier dysfunction, oxidants will reduce the fluidity of the plasma membrane and induce lipid peroxidation, leading to the leakage of ions and water from the membrane (133). Oxidants can also cause DNA strand breaks, precipitate endothelial contraction by activating the RhoA and MLCK pathways, weaken interendothelial connections and cell-ECM adhesion through multiple signaling pathways (Src, RhoA, PLC, Ca2+, MAPK, and MLCK), and mediate the destruction of microvascular endothelial permeability $(134,135)$.

The clinical application of antioxidants has been very extensive. Antioxidant therapy alone, such as application of ascorbic acid, glutathione, acetylcysteine, and vitamins, can improve the survival rate of burn patients. Rehou et al. demonstrated that patients who received antioxidant and trace element supplementation had lower levels of markers of stress-induced inflammation after burn injury compared with those who did not receive this treatment. These therapies were also associated with reduced hypermetabolic response, shortened hospital stay, and increased bacterial clearance (136). At present, there are many antioxidant therapies commonly used in the treatment of burns. Ascorbic acid, glutathione, $\mathrm{N}$-acetylL-cysteine, or vitamins $\mathrm{A}, \mathrm{E}$, and $\mathrm{C}$ can be used alone or in combination with other drugs, and can reduce cellular energy change, protect microvascular circulation, reduce tissue lipid peroxidation, increase cardiac output, and reduce the volume of fluid resuscitation required (137). New antioxidants are also being continuously studied. Scholars such as Ghlissi used Globularia alypum (GA)methanol extract (GAME) to treat second-degree burn rats. The results showed that the healing activity of burn wounds increased, which might have been due to GAME's antiinflammatory, antibacterial, and antioxidant activities (138). Carter et al. used a tetrapeptide D-Arg-Dmt-Lys-PheNH2 (SS31) with antioxidant properties to observe the antagonistic effect on insulin resistance induced by burns in mice, which laid the foundation for the research on the other effects of SS31 (139). Ben Slima et al. studied the structural characteristics of a new polysaccharide sorghum water-soluble polysaccharide (SWSP) extracted from sorghum seeds. The test of three parameters (iron chelating activity, reducing power, and DNA etching) showed that SWSP has strong antioxidative activity (140). The oxidantmediated vascular permeability of antioxidants has not been extensively studied, but the continuous development of new antioxidants will inevitably open new avenues in this 
research.

\section{Lipopolysaccharide (LPS)}

LPS is the structural component of the outer membrane of Gram-negative bacteria, which are also known endotoxins. Gram-negative bacteria grow in heat-damaged tissues after burns with the endotoxin entering the bloodstream, which can cause vasodilation dysfunction and EC apoptosis, coagulation activation, and fibrin deposition, finally leading to sepsis (141). The study of Gram-negative sepsis induced by Escherichia coli revealed that CD18 integrin is involved in the permeability of lung microvascular induced by $E$. coli and can amplify the separation and migration of lung neutrophils in a time-dependent manner, but it is a necessary mechanism (142). An endotoxin-induced rat pulmonary vascular EC gap increase model has confirmed that heat shock protein 27 (HSP27) depends on its phosphorylation state to regulate the dynamics or structure of actin filaments, thereby affecting the connection between the endothelium and mediating the increase in the permeability of the vascular endothelial barrier (143). Other cell experiments have shown that the Rho-GTPase inhibitor C3 transferase of Clostridium botulinum or the Rho kinase inhibitor, Y-27632, can block EC contraction, actin reorganization, and loss of endothelial integrity caused by endotoxins. This suggests that the endotoxin-mediated increase in vascular endothelial permeability partly depends on the phosphorylation of RhoA's MLC (144). In addition, studies have also suggested that endotoxin-mediated increases in vascular endothelial permeability are closely related to EC F-actin depolymerization, actin filament reorganization, and protein tyrosine phosphorylation $(145,146)$. In fact, when endotoxins are active in circulation, their mechanism of action on vascular endothelium is multifaceted. Endotoxins can activate the release of a series of inflammatory mediators through a transcription mechanism involving NF- $\beta$ B activation. The release of mediators such as TNF- $\beta$, IL- 1 , and IL- 8 further affects vascular endothelial permeability. Research by Walton et al. found that the overexpression of CAV-1 could increase the production of IL-8 induced by endotoxins, which is closely related to the complex role of caveolin, a key molecule in the transcellular pathway (147). Peng et al. applied an endotoxin-mediated acute lung injury mouse model and found that sphingosine1-phosphate (S1P) could significantly reduce vascular leakage and inflammation, introducing a possible strategy to mitigate the damage to the endothelial barrier caused by endotoxins (148).

In clinical practice, patients with severe burn injury are given timely scabs and skin grafts to clear necrotic tissues and infections, reasonable antibiotic therapy, nutrition support treatment, and other comprehensive measures to reduce endotoxin level, thereby protecting and improving the function of the vascular endothelial barrier.

\section{VEGF}

After the body is burned, the serum VEGF level immediately increases and continues to rise until the wound is healed. The VEGF level reaches its peak on the 14th day, which can reach 22 times the healthy level (149). VEGF is a mitogen of vascular ECs derived from arteries, veins, and lymphatic vessels, and lacks continuous mitotic activity on other types of cells (150). VEGF can promote angiogenesis, induce fused microvascular ECs to invade the collagen gel and form a capillary-like structure, and is one of the important mediators for increasing the permeability of the vascular endothelial barrier (151). As a homodimer, VEGF binds to three different receptors to stimulate EC mitosis and migration, and increases the permeability of the endothelial monolayer (152). In vitro studies have confirmed that VEGF can stimulate phospholipase C and A (PLC and PLA, respectively), protein kinase $\mathrm{B}$, mitogen activated protein kinase (MAPK), focal adhesion kinase (FAK), $\mathrm{Ca}^{2+}$, nitric oxide, protein kinase $\mathrm{C}$ (PKC), and many other pathways (153). Although many in vitro experiments have confirmed the mechanism of action of the above-mentioned multi-signal pathways of VEGF, due to the complexity of the in vivo environment and many influencing factors, there are still many difficulties in in vivo experiments to confirm the above pathways.

In recent years, studies have been performed on EC growth factor inhibitors or EC growth factor receptors, and significant research progress has been made. Gomez Perdiguero et al. studied the effect of angiopoietinlike protein 4 (ANGPTL4) on the regulation of vessel integrity. The results showed that angiopoietin-like protein 4 binds to integrin $\alpha v \beta 3$ to form ANGPTL4- $\alpha v \beta 3$, and the binding enhances the recruitment of integrin $\alpha v \beta 3$ by Src and inhibits the downstream Src signal transduction of VEGFR2, thereby inhibiting the decomposition of VEGFR2-VE cadherin and VEGFR2- $\alpha$ v $\beta 3$ complex induced by hypoxia, and thus increasing the adhesion connection and integrity of tight connections. This suggests that the newly discovered Angptl4- $\alpha v \beta 3$ axis may be one 
of the targets of drug intervention in vascular endothelial permeability under pathological conditions (154). Angulo et al. evaluated the effect of 2,5-hydroxybenzene sulfonate (DHBS) on the induction of VEGF. The study found that coadministration of DHBS $(200 \mu \mathrm{M})$ could inhibit the enhancement effect of VEGF $(50 \mu \mathrm{L}, 10 \mathrm{ng} / \mathrm{mL})$ on rat skin vascular permeability, which suggests that DHBS, as a dual antagonist of $\mathrm{VEGF}$ and fibroblast growth factor (FGF), may be useful in the treatment of VEGF/FGFrelated diseases (155). In the field of oncology, research on anti-VEGF drugs such as ranibizumab, bevacizumab, and pegaptanib has been extensive, with some of these drugs being applied in clinical tumor targeted therapy. The application of anti-VEGF drugs in other fields are also gradually being carried out. Rodrigues et al. studied the anti-VEGF effect of abicipar, which is a designed ankyrin repeat protein (DARPins) that targets VEGF- $\alpha$. The results of cell-based and in vivo angiogenesis and vascular leakage models suggest that abicipar is effective to block new blood vessels in a mouse corneal neovascularization model and to reduce vascular permeability in the rabbit model of chronic neovascularization (156).

\section{Thrombin}

After the body is severely burned, the decrease in anticoagulant activity and the production of a large amount of thrombin may simultaneously occur, with these processes being closely related to the severity of the burn (157). Thrombin is produced by proteolysis of inactivated zymogen by factor $\mathrm{V}$ and factor $\mathrm{X}$ with the help of cofactor $\mathrm{Ca}^{2+}$ and membrane phospholipids. It is a procoagulant serine protease that is active in increasing vascular endothelial permeability (158). Thrombin usually exists in the circulation for a short time, with a half-life of about 5 minutes, and can be eliminated by activated protein $\mathrm{C}$. Therefore, thrombin is released into the blood after tissue burns, which often causes a local increase in vascular permeability. However, thrombin can be highly concentrated in the fibrin clot. Therefore, in the process of thrombus formation and clot fibrinolysis, thrombin is more likely contribute to increased permeability of the blood vessel wall (159). Thrombin binds to protease activated receptor-1 (PAR-1) on vascular ECs, induces PAR-1 extracellular extension, initiates downstream signals, and increases transendothelial cell permeability, endothelial contraction, and permeability of blood vessel endothelium (160). The dependence of thrombin on the activation of PAR- 1 has been further verified in the study of pulmonary microvascular permeability in the PAR-1 gene (PAR-1-/-)-deficient mice (161). PAR-1 has seven transmembrane domains unique to all G-proteincoupled receptors, and its function is regulated by receptor proteolysis, phosphorylation, internalization, and degradation.

Antithrombin combines with thrombin to form a thrombin-antithrombin complex (TAT), and studies on TAT and coagulation mechanism have been ongoing for many years. The research on antagonizing thrombin to increase the permeability of vascular ECs has mostly focused on the PAR1 signaling pathway. Extracting cocoons from PAR-1 and the downstream complex signaling pathways and continually elucidating its mechanism of action are critical in the search for targets in regulating vascular endothelial permeability.

\section{Prospects of applying ulinastatin for improving vascular endothelial permeability in the early stage of burn}

Ulinastatin (UTI) is a $67 \mathrm{kDa}$ glycoprotein of Kunitz type with protease inhibitor action. It was first isolated from human urine. UTI contains two active functional domains. The overlapping area has biological activity on a wide range of enzymes (162). UTI can inhibit the activity of a variety of enzymes, such as $\alpha$-chymotrypsin, hyaluronidase, plasmin, neutrophil elastase. It also stabilizes lysosomal membranes, inhibits the release of lysosomal enzymes, and reduces the production of myocardial inhibitors. It can also intervene with inflammatory mediators in multiple signaling pathways (163). UTI has now been widely used in the fields of acute and critical illness, sepsis, and organ transplantation, and plays an important role in organ protection and immune regulation $(164,165)$. We know that the local and systemic vascular permeability increases rapidly after severe burns, the extravasation of intravascular fluid and protein components can reach a peak after 8 hours, and a large amount of fluid is required in a short period of time to combat the rapidly progressing shock. However, complicated external factors often cause delayed fluid resuscitation, leading to serious consequences. Therefore, finding an effective method to delay or inhibit the increase in vascular permeability after burns and buy time for resuscitation of burn shock has important clinical significance, especially when treating the wounded in the field or in batches of wounded patients. In view of the positive effects of UTI in improving circulation, inhibiting inflammation and organ perfusion, and blocking the 
progress of systemic inflammatory response syndrome and multiple organ dysfunction syndrome (SIRS/MODS), we will focus on the improvement of vascular endothelial permeability in the early stages of burns.

We have briefly introduced the mechanism of TNF- $\alpha$ in vascular permeability changes after severe burns. A number of current basic and clinical studies have proved that UTI can play a therapeutic role in antagonizing TNF- $\alpha$. First, UTI can inhibit the production of endogenous TNF- $\alpha$ in pulmonary capillary ECs. Pulmonary ECs are considered to be an inflammatory cell that produces TNF- $\alpha$, which is often found in septic lung tissues. The accumulation of a large number of M1 phenotype lung macrophages may be the main source of TNF- $\alpha$. UTI has been shown to mediate the polarization of macrophages from M1 to M2 phenotype (166). In addition, after burns, TNF- $\alpha$ can activate RhoA/ROCK2 pathway through protein kinase $\mathrm{C}-\alpha$, and ROCK2 pathway can cause the myosin phosphatase to target subunit-1 phosphorylation (167), leading to actin-myosin crosslinking, microfilament sliding, and cell contraction, resulting in damage to the connections between vascular ECs and increased permeability of vascular ECs (120). Wei et al. established RhoA overexpression lentivirus and observed the effect of UTI on the key proteins of the Rho/ROCK signaling pathway, and confirmed that UTI regulates TNF- $\alpha$-induced vascular EC permeability disorder, the mechanism of which is centered in the Rho/ROCK signaling pathway (168). In addition, after severe burns, NF- $\kappa \mathrm{B}$ is activated in a relatively inactive state. $\mathrm{NF}-\mathrm{\kappa B}$, as a transcription factor related to regulating innate immune response and adaptive immune response, can directly or indirectly regulate the expression of TNF- $\alpha$ in inflammatory cells. However, when UTI is used for intervention, the expression of NF- $\mathrm{\kappa B}$ and tumor necrosis factor- $\alpha$ is downregulated. Therefore, studies have speculated that one of the mechanisms work through the inhibition of NF- $\kappa-\mathrm{B}$, leading to reduce TNF- $\alpha$ expression, thereby suppressing the inflammatory response (169). In addition, studies have found that in the model of ischemiareperfusion injury, UTI can inhibit the P38 mitogenactivated protein kinase (P38MAPK) signaling pathway and c-Jun amino-terminal kinase (JNK) signaling pathway to exert myocardial protection, and this effect may be mediated by UTI downregulating the expression of TNF- $\alpha$ (170). It can be seen that TNF- $\alpha$ exerts its biological activity in various pathological states through multiple pathways in acute inflammation after burns, and the antagonistic effect of UTI on TNF- $\alpha$ is somewhat similar. Overall, the relevant research suggests that UTI may play multiple roles by inhibiting the production of endogenous and exogenous TNF- $\alpha$ (171).

After severe burns, macrophages and neutrophils release a large number of oxidants such as hydrogen peroxide $\mathrm{H}_{2} \mathrm{O}_{2}$, superoxide $\mathrm{O}^{2-}$, and hydroxyl radicals $-\mathrm{OH}$, which disrupt cell membrane function through neutrophil adhesion and lipid peroxidation. This can also destroy the interstitium by fragmenting the interstitial lattice of hyaluronic acid, affecting the interendothelial connection and cell-ECM adhesion, and mediating the destruction of microvascular endothelial permeability. Studies have confirmed that UTI can inhibit the formation of ROS induced by oxidants, through preventing the leakage of JC-1 from mitochondria to the cytoplasm, increasing the level of intracellular ATP to protect mitochondrial function, reducing the release of cytochrome $\mathrm{c}$ from mitochondria to the cytoplasm, inhibiting the activation of cysteine protease-3, and preventing the destruction of AJs (172), finally increasing the permeability of vascular endothelium mediated by antioxidants. Luo et al. found that UTI infusion significantly reduced the plasma and tissue concentrations of thiobarbituric acid reactive substances (TBARS) in post-burn miniature pig models, suggesting that UTI can decrease vascular permeability possibly by inhibiting burn-induced lipid peroxidation (173). In recent years, some studies have been conducted on the protective effect of UTI on cell apoptosis, but the detailed mechanism of UTI's ability to inhibit the formation of reactive oxygen mediators induced by oxidants and its relationship with apoptosis remain to be clarified by future research. We know that oxidants are also involved in the release of histamine after severe burns. Then, theoretically, UTI can reduce the release of histamine in patients with severe burns by inhibiting the formation of active oxygen mediators induced by oxidants, thereby intervening in histamine-mediated vascular endothelial permeability after burns; however, this speculation requires further verification. Furthermore, the timing and dosage of UTI treatment after severe burns and their effects remain controversial. Research by Itagaki et al. found that the application of superoxide dismutase to burn mice immediately after the burn could inhibit the generation of ROS, thereby reducing lung injury 6 hours after the burn. Therefore, applying UTI immediately after burn injury and evaluating the generation of ROS and the subsequent changes in vascular permeability and organ injury may be helpful in determining the most appropriate time to use UTI after burns (174). In addition, the dosage of UTI in the drug instruction manual is 100,000 units 1 to 3 
Table 1 Summary of this review

\begin{tabular}{ll}
\hline Factors & Roles \\
\hline Histological basis of microvascular endothelial barrier \\
Microvascular ECs & $\begin{array}{l}\text { histological basis for changes in } \\
\text { microvascular permeability }\end{array}$ \\
$\begin{array}{ll}\text { Endothelial surface } & \text { Important part of the microvascular } \\
\text { layer } & \text { endothelial barrier } \\
\text { Endothelial } & \text { Can regulate oxygen transport in a } \\
\text { glycocalyx } & \text { charge-dependent manner and protect } \\
\text { the endothelium from leukocyte adhesion } & \\
\text { Basement } & \text { Supports material for vascular ECs and } \\
\text { membrane } & \text { also separates vascular ECs from the } \\
& \text { underlying tissues } \\
\text { Extracellular matrix } & \text { Changes in ECM mechanics affect } \\
\text { (ECM) } & \text { pulmonary vascular permeability }\end{array}$
\end{tabular}

Microvascular endothelial transport pathways

$\begin{array}{ll}\begin{array}{l}\text { Transcellular } \\ \text { pathway }\end{array} & \begin{array}{l}\text { Is responsible for the normal and } \\ \text { physiological transendothelial transport of } \\ \text { macromolecules }\end{array} \\ \begin{array}{l}\text { Paracellular } \\ \text { pathway }\end{array} & \begin{array}{l}\text { Mediates the transport of water and } \\ \text { solutes from ions to macromolecules }\end{array} \\ \begin{array}{l}\text { Burn-related agonists mediate increased microvascular } \\ \text { permeability }\end{array} & \\ \text { Histamine } & \begin{array}{l}\text { Increases the permeability of } \\ \text { microvascular endothelium }\end{array} \\ \text { Bradykinin } & \text { Increase the permeability of microvascular } \\ & \text { ECs }\end{array}$

Tumor necrosis Induces thymocyte apoptosis; involved in factor- $\alpha$ (TNF- $\alpha)$ bone loss after severe burns; upregulate ICAM-1 and E-selectin; increase the permeability of microvascular ECs

Oxidants Damage vascular ECs

Lipopolysaccharide Causes vasodilation dysfunction and EC (LPS) apoptosis, coagulation activation, and fibrin deposition, finally leading to sepsis

VEGF Increases the permeability of the vascular endothelial barrier

Thrombin Increases transendothelial cell permeability, endothelial contraction, and permeability of blood vessel endothelium

Prospects of applying ulinastatin for improving vascular endothelial permeability in the early stage of burn

Ulinastatin Improves circulation, inhibiting inflammation and organ perfusion, and blocking the progress of systemic inflammatory response syndrome and multiple organ dysfunction syndrome; improves vascular endothelial permeability times a day. In actual clinical work and animal experimental studies, a larger dose may achieve better therapeutic effects. Research on the dosage of UTI also has practical clinical significance.

Finally, UTI can reduce the level of IL- 6 in the monolayer pulmonary capillary ECs treated with scalded serum or trypsin. IL-6 participates in the cascade of inflammation and changes in vascular permeability after burns through macrophages, liver cells, resting $\mathrm{T}$ cells, activated B cells, and other target cells (175). UTI can exert its effects through multiple channels and different stages, delaying or inhibiting the increase in vascular permeability after burns, and buying time for the recovery of burn shock. The detailed mechanism of UTI's effect, timing, and dosage, still need to be further studied.

\section{Discussion}

In the continuous exploration of the field of vascular endothelial pathophysiology, many studies have produced results of practical clinical significance. However, due to the complexity of the regulation mechanism of vascular endothelial permeability, there are still many problems that need to be explored, and many mechanisms have not yet been elucidated. This article discusses the mechanism underlying the increase in vascular permeability caused by severe burns in the body. In short, the increase in vascular permeability after burns is the result of the combined stimulation of multiple agonists and the superimposition of multiple signal pathways. This response to increased vascular permeability is a response to a physiological defense mechanism. Increasing permeability can allow plasma albumin, immunoglobulin, and other mediators with host defense functions to leak into the tissue interstitium. However, excessive permeability can also lead to a series of severe pathological changes such as hypoalbuminemia, protein-rich tissue edema, and organ dysfunction. Therefore, the adjustment of vascular permeability after severe burns is one of the key directions of burn treatment research. Currently known mediators capable of stabilizing the endothelial barrier, such as S1P (174) and angiotensin converting enzyme-1 (175), have little clinical significance in practice, and further studies are needed in this regard. We summarized the main point of this review in Table 1.

\section{Acknowledgments}

Funding: The Major Military Logistics Scientific Research 
Project "Application research of new materials and technologies in the treatment of ammunition and firearm injuries in wartime" (No. ALB19J001).

\section{Footnote}

Reporting Checklist: The authors have completed the Narrative Review reporting checklist. Available at http:// dx.doi.org/10.21037/atm-21-1267

Conflicts of Interest: All authors have completed the ICMJE uniform disclosure form (available at http://dx.doi. org/10.21037/atm-21-1267). The authors have no conflicts of interest to declare.

Ethical Statement: The authors are accountable for all aspects of the work in ensuring that questions related to the accuracy or integrity of any part of the work are appropriately investigated and resolved.

Open Access Statement: This is an Open Access article distributed in accordance with the Creative Commons Attribution-NonCommercial-NoDerivs 4.0 International License (CC BY-NC-ND 4.0), which permits the noncommercial replication and distribution of the article with the strict proviso that no changes or edits are made and the original work is properly cited (including links to both the formal publication through the relevant DOI and the license). See: https://creativecommons.org/licenses/by-nc-nd/4.0/.

\section{References}

1. Wang Y, Maitz PKM. Advances and new technologies in the treatment of burn injury. Adv Drug Deliv Rev 2018;123:1-2.

2. Rae L, Fidler P, Gibran N. The Physiologic Basis of Burn Shock and the Need for Aggressive Fluid Resuscitation. Crit Care Clin 2016;32:491-505.

3. Zavlin D, Chegireddy V, Boukovalas S, et al. Multiinstitutional analysis of independent predictors for burn mortality in the United States. Burns Trauma 2018;6:24.

4. Swanson JW, Otto AM, Gibran NS, et al. Trajectories to death in patients with burn injury. J Trauma Acute Care Surg 2013;74:282-8.

5. Duran WN, Sanchez FA, Breslin JW. Microcirculatory Exchange Function In Handbook of Physiology: Microcirculation, 2nd ed, 2008:81-124.

6. Evans EI, Purnell OJ, Robinett PW, et al. Fluid and electrolyte requirements in severe burns. Ann Surg 1952;135:804-17.

7. Korov I. Etiology and pathogenesis of burn shock. Eksp Khirurgiia 1956;1:49-54.

8. Gurney JM, Kozar RA, Cancio LC. Plasma for burn shock resuscitation: is it time to go back to the future? Transfusion 2019;59:1578-86.

9. Klusmeier N, Schnittler HJ, Seebach J. A Novel Microscopic Assay Reveals Heterogeneous Regulation of Local Endothelial Barrier Function. Biophys J 2019;116:1547-59.

10. Alves NG, Motawe ZY, Yuan SY, et al. Endothelial Protrusions in Junctional Integrity and Barrier Function. Curr Top Membr 2018;82:93-140.

11. Claesson-Welsh L, Dejana E, McDonald DM. Permeability of the Endothelial Barrier: Identifying and Reconciling Controversies. Trends Mol Med 2020;27:314-31.

12. Sturtzel C. Endothelial Cells. Adv Exp Med Biol 2017;1003:71-91.

13. Vink H, Duling BR. Capillary endothelial surface layer selectively reduces plasma solute distribution volume. Am J Physiol Heart Circ Physiol 2000;278:H285-9.

14. Kurzelewski M, Czarnowska E, Beresewicz A. Superoxideand nitric oxide-derived species mediate endothelial dysfunction, endothelial glycocalyx disruption, and enhanced neutrophil adhesion in the post-ischemic guineapig heart. J Physiol Pharmacol 2005;56:163-78.

15. Van Teeffelen JW, Brands J, Stroes ES, et al. Endothelial glycocalyx: sweet shield of blood vessels. Trends Cardiovasc Med 2007;17:101-5.

16. Huxley VH, Williams DA. Role of a glycocalyx on coronary arteriole permeability to proteins: evidence from enzyme treatments. Am J Physiol Heart Circ Physiol 2000;278:H1177-85.

17. Luft JH. Fine structures of capillary and endocapillary layer as revealed by ruthenium red. Fed Proc 1966;25:1773-83.

18. Weinbaum S, Tarbell JM, Damiano ER. The structure and function of the endothelial glycocalyx layer. Annu Rev Biomed Eng 2007;9:121-67.

19. Damiano ER. The effect of the endothelial-cell glycocalyx on the motion of red blood cells through capillaries. Microvasc Res 1998;55:77-91.

20. Pries AR, Secomb TW, Gaehtgens P. The endothelial surface layer. Pflugers Arch 2000;440:653-66.

21. Arisaka T, Mitsumata M, Kawasumi M, et al. Effects of shear stress on glycosaminoglycan synthesis in vascular 
endothelial cells. Ann N Y Acad Sci 1995;748:543-54.

22. Florian JA, Kosky JR, Ainslie K, et al. Heparan sulfate proteoglycan is a mechanosensor on endothelial cells. Circ Res 2003;93:e136-42.

23. Dull RO, Dinavahi R, Schwartz L, et al. Lung endothelial heparan sulfates mediate cationic peptide-induced barrier dysfunction: a new role for the glycocalyx. Am J Physiol Lung Cell Mol Physiol 2003;285:L986-L995.

24. Henry CB and Duling BR. TNF-alpha increases entry of macromolecules into luminal endothelial cell glycocalyx. Am J Physiol Heart Circ Physiol 2000;279:H2815-H2823.

25. Sieve I, Münster-Kühnel AK, Hilfiker-Kleiner D. Regulation and function of endothelial glycocalyx layer in vascular diseases. Vascul Pharmacol 2018;100:26-33.

26. Rahbar E, Cardenas JC, Baimukanova G, et al. Endothelial glycocalyx shedding and vascular permeability in severely injured trauma patients. J Transl Med 2015;13:117.

27. Zhao H, Zhu Y, Zhang J, et al. The Beneficial Effect of HES on Vascular Permeability and Its Relationship With Endothelial Glycocalyx and Intercellular Junction After Hemorrhagic Shock. Front Pharmacol 2020;11:597.

28. Jacob M, Saller T, Chappell D, et al. Physiological levels of A-, B- and C-type natriuretic peptide shed the endothelial glycocalyx and enhance vascular permeability. Basic Res Cardiol 2013;108:347.

29. Kahsai TZ, Enders GC, Gunwar S, et al. Seminiferous tubule basement membrane. Composition and organization of type IV collagen chains, and the linkage of alpha3(IV) and alpha5(IV) chains. J Biol Chem 1997;272:17023-32.

30. Miner JH, Li C, Mudd JL, et al. Compositional and structural requirements for laminin and basement membranes during mouse embryo implantation and gastrulation. Development 2004;131:2247-56.

31. Kalluri R. Basement membranes: structure, assembly and role in tumour angiogenesis. Nat Rev Cancer 2003;3:422-33.

32. Albelda SM, Daise M, Levine EM, et al. Identification and characterization of cell-substratum adhesion receptors on cultured human endothelial cells. J Clin Invest 1989;83:1992-2002.

33. Mammoto A, Mammoto T, Kanapathipillai M, et al. Control of lung vascular permeability and endotoxininduced pulmonary oedema by changes in extracellular matrix mechanics. Nat Commun 2013;4:1759.

34. Qiao R, Siflinger-Birnboim A, Lum H, et al. Albumin and Ricinus communis agglutinin decrease endothelial permeability via interactions with matrix. Am J Physiol 1993;265:C439-C446.

35. Hendel A, Hsu I, Granville DJ. Granzyme B releases vascular endothelial growth factor from extracellular matrix and induces vascular permeability. Lab Invest 2014;94:716-25.

36. Hahn CS, Scott DW, Xu X, et al. The matrikine N- -PGP couples extracellular matrix fragmentation to endothelial permeability. Sci Adv 2015;1:e1500175.

37. Resnikoff M, Brien T, Vincent PA, et al. Lung matrix incorporation of plasma fibronectin reduces vascular permeability in postsurgical bacteremia. Am J Physiol 1999;277:L749-L759.

38. Qiao RL, Wang HS, Yan W, et al. Extracellular matrix hyaluronan is a determinant of the endothelial barrier. Am J Physiol 1995;269:C103-C109.

39. Simionescu M, Simionescu N. Endothelial transport of macromolecules: transcytosis and endocytosis. A look from cell biology. Cell Biol Rev 1991;25:1-78.

40. Simionescu N. Cellular aspects of transcapillary exchange. Physiol Rev 1983;63:1536-79.

41. Tuma P, Hubbard AL. Transcytosis: crossing cellular barriers. Physiol Rev 2003;83:871-932.

42. Minshall RD, Tiruppathi C, Vogel SM, et al. Endothelial cell-surface gp60 activates vesicle formation and trafficking via $G(i)$-coupled Src kinase signaling pathway. J Cell Biol 2000;150:1057-70.

43. Hu G, Minshall RD. Regulation of transendothelial permeability by Src kinase. Microvasc Res 2009;77:21-5.

44. Boscher C, Nabi IR. Caveolin-1: role in cell signaling. Adv Exp Med Biol 2012;729:29-50.

45. Yi SL, Liu XJ, Zhong JQ, et al. Role of caveolin-1 in atrial fibrillation as an anti-fibrotic signaling molecule in human atrial fibroblasts. PLoS One 2014;9:e85144.

46. Gu X, Reagan AM, McClellan ME, et.al. Caveolins and caveolae in ocular physiology and pathophysiology. Prog Retin Eye Res 2017;56:84-106.

47. Drab M, Verkade P, Elger M, et al. Loss of caveolae, vascular dysfunction, and pulmonary defects in caveolin-1 gene-disrupted mice. Science 2001;293:2449-52.

48. Minetti C, Bado M, Broda P, et al. Impairment of caveolae formation and T-system disorganization in human muscular dystrophy with caveolin-3 deficiency. Am J Pathol 2002;160:265-70.

49. Razani B, Engelman JA, Wang XB, et al. Caveolin-1 null mice are viable but show evidence of hyperproliferative and vascular abnormalities. J Biol Chem 2001;276:38121-38.

50. Ariotti N, Rae J, Leneva N, et al. Molecular characterization of caveolin-induced membrane curvature. J Biol Chem 2015;290:24875-90

51. Parton RG, Tillu VA, Collins BM. Caveolae. Curr Biol 
2018;28:R402-R405.

52. Mayor S, Parton RG, Donaldson JG. Clathrinindependent pathways of endocytosis. Cold Spring Harb Perspect Biol 2014;6:a016758.

53. Hu G, Vogel SM, Schwartz DE, et al. Intercellular adhesion molecule-1-dependent neutrophil adhesion to endothelial cells induces caveolae-mediated pulmonary vascular hyperpermeability. Circ Res 2008;102:e120-31.

54. Cattaneo MG, Vanetti C, Decimo I, et al. Sex-specific eNOS activity and function in human endothelial cells. Sci Rep 2017;7:9612.

55. Bernatchez P, Sharma A, Bauer PM, et al. A noninhibitory mutant of the caveolin-1 scaffolding domain enhances eNOS-derived NO synthesis and vasodilation in mice. J Clin Invest 2011;121:3747-55.

56. Trane AE, Pavlov D, Sharma A, et al. Deciphering the binding of caveolin-1 to client protein endothelial nitric-oxide synthase (eNOS): scaffolding subdomain identification, interaction modeling, and biological significance. J Biol Chem 2014;289:13273-83.

57. Zhang J, Jiang Z, Bao C, et al. Cardiopulmonary bypass increases pulmonary microvascular permeability through the Src kinase pathway: Involvement of caveolin-1 and vascular endothelial cadherin. Mol Med Rep 2016;13:2918-24.

58. Wang N, Zhang D, Sun G, et al. Lipopolysaccharideinduced caveolin-1 phosphorylation-dependent increase in transcellular permeability precedes the increase in paracellular permeability. Drug Des Devel Ther 2015;9:4965-77.

59. Jones JH, Friedrich E, Hong Z, et al. PV1 in Caveolae Controls Lung Endothelial Permeability. Am J Respir Cell Mol Biol 2020;63:531-9.

60. Chambers R, Zweifach BW. Intercellular cement and capillary permeability. Physiol Rev 1947;27:436-63.

61. Curry FE, Michel CC. A fiber matrix model of capillary permeability. Microvasc Res 1980;20:96-9.

62. DeMali KA and Burridge K. Coupling membrane protrusion and cell adhesion. J Cell Sci 2003;116:2389-97.

63. Geiger B, Bershadsky A, Pankov R, et al. Transmembrane crosstalk between the extracellular matrix-cytoskeleton crosstalk. Nat Rev Mol Cell Biol 2001;2:793-805.

64. Bazzoni G, Dejana E. Endothelial cell-to-cell junctions: molecular organization and role in vascular homeostasis. Physiol Rev 2004;84:869-901.

65. Wójciak-Stothard B, Potempa S, Eichholtz T, et al. Rho and Rac but not Cdc42 regulate endothelial cell permeability. J Cell Sci 2001;114:1343-55.
66. Dejana E, Spagnuolo R, Bazzoni G. Interendothelial junctions and their role in the control of angiogenesis, vascular permeability and leukocyte transmigration. Thromb Haemost 2001;86:308-15.

67. Corada M, Liao F, Lindgren M, et al. Monoclonal antibodies directed to different regions of vascular endothelial cadherin extracellular domain affect adhesion and clustering of the protein and modulate endothelial permeability. Blood 2001;97:1679-84.

68. Noren NK, Arthur WT, Burridge K. Cadherin engagement inhibits RhoA via p190 RhoGAP. J Biol Chem 2003;278:13615-8.

69. Iyer S, Ferreri DM, DeCocco NC, et al. VEcadherin-p120 interaction is required for maintenance of endothelial barrier function. Am J Physiol Lung Cell Mol Physiol 2004;286:L1143-L1153.

70. Schneeberger EE. Structure of intercellular junctions in different segments of the intrapulmonary vasculature. Ann NY Acad Sci 1982;384:54-63.

71. Furuse M, Itoh M, Hirase T, et al. Direct association of occludin with ZO-1 and its possible involvement in the localization of occludin at tight junctions. J Cell Biol 1994;127:1617-26.

72. Van Itallie CM, Anderson JM. Occludin confers adhesiveness when expressed in fibroblasts. J Cell Sci 1997;110:1113-21.

73. Liu Y, Nusrat A, Schnell FJ, et al. Human junction adhesion molecule regulates tight junction resealing in epithelia. J Cell Sci 2000;113:2363-74.

74. Majno G, Palade G. Studies on inflammation I. The effect of histamine and serotonin on vascular permeability: an electron microscopic study. J Biophys Biochem Cytol 1961;11:571-605.

75. Shen Q, Wu MH, Yuan SY. Endothelial contractile cytoskeleton and microvascular permeability. Cell Health Cytoskelet 2009;2009:43-50.

76. Dudek SM, Garcia JG. Cytoskeletal regulation of pulmonary vascular permeability. J Appl Physiol 2001;91:1487-500.

77. Moy AB, Van Engelenhoven J, Bodmer J, et al. Histamine and thrombin modulate endothelial focal adhesion through centripetal and centrifugal forces. J Clin Invest 1996;97:1020-7.

78. Birukova AA, Birukov KG, Smurova K, et al. Novel role of microtubules in thrombin-induced endothelial barrier dysfunction. FASEB J 2004;18:1879-90.

79. Dejana E. Endothelial cell-cell junctions: happy together. Nat Rev Mol Cell Biol 2004;5:261-70. 
80. Gao X, Kouklis P, Xu N, et al. Reversibility of increased microvessel permeability in response to VE-cadherin disassembly. Am J Physiol Lung Cell Mol Physiol 2000;279:L1218-L1225.

81. Zheng YJ, Xu WP, Ding G, et al. Expression of HMGB1 in septic serum induces vascular endothelial hyperpermeability. Mol Med Rep 2016;13:513-21.

82. Tauseef M, Farazuddin M, Sukriti S, et al. Transient receptor potential channel 1 maintains adherens junction plasticity by suppressing sphingosine kinase 1 expression to induce endothelial hyperpermeability. FASEB J 2016;30:102-10.

83. Arturson G. Pathophysiology of the burn wound and pharmacological treatment. The Rudi Hermans Lecture 1995. Burns 1996;22:255-74.

84. Jewo PI, Fadeyibi IO. Progress in burns research: a review of advances in burn pathophysiology. Ann Burns Fire Disasters 2015;28:105-15.

85. Zhao J, Chen L, Shu B, et al. Granulocyte/macrophage colony-stimulating factor attenuates endothelial hyperpermeability after thermal injury. Am J Transl Res 2015;7:474-88.

86. Morgan M, Deuis JR, Frøsig-Jørgensen M, et al. Burn Pain: A Systematic and Critical Review of Epidemiology, Pathophysiology, and Treatment. Pain Med 2018;19:708-34.

87. Demling RH. The burn edema process: current concepts. J Burn Care Rehabil 2005; 26:207-27.

88. Gibran NS, Heimbach DM. Mediators in thermal injury. Semin Nephrol 1993;13:344-58.

89. Arturson G. Forty years in burns research - the postburn inflammatory response. Burns 2000;26:599-604.

90. Hill SJ. Distribution, properties, and functional characteristics of three classes of histamine receptor. Pharmacol Rev 1990;42:45-83.

91. Hill SJ, et al. International Union of Pharmacology. XIII. Classification of histamine receptors. Pharmacol Rev 1997;49:253-78.

92. Hekimian G, Cote S, Van Sande J, et al. H2 receptormediated responses of aortic endothelial cells to histamine. Am J Physiol 1992;262:H220-H224.

93. Hu Q, Natarajan V, Ziegelstein RC. Phospholipase D regulates calcium oscillation frequency and nuclear factorkappaB activity in histamine-stimulated human endothelial cells. Biochem Biophys Res Commun 2002;292:325-32.

94. Wu MH, Yuan SY, Granger HJ. The protein kinase MEK1/2 mediate vascular endothelial growth factor- and histamine-induced hyperpermeability in porcine coronary venules. J Physiol 2005;563:95-104.
95. Guo M, Breslin JW, Wu MH, et al. VE-cadherin and beta-catenin binding dynamics during histamine-induced endothelial hyperpermeability. Am J Physiol Cell Physiol 2008;294:C977-C984.

96. McDonald DM, Thurston G, and Baluk P. Endothelial gaps as sites for plasma leakage in inflammation. Microcirculation 1999;6:7-22.

97. Boykin JV Jr, Eriksson E, Sholley MM, et al. Histaminemediated delayed permeability response after scald burn inhibited by cimetidine or cold-water treatment. Pittman RN. Science 1980;209:815-7.

98. Reynoso R, Perrin RM, Breslin JW, et al. A role for long chain myosin light chain kinase (MLCK-210) in microvascular hyperpermeability during severe burns. Shock 2007;28:589-95.

99. Chen W, Oberwinkler H, Werner F, et al. Atrial natriuretic peptide-mediated inhibition of microcirculatory endothelial $\mathrm{Ca} 2+$ and permeability response to histamine involves cGMP-dependent protein kinase I and TRPC6 channels. Arterioscler Thromb Vasc Biol 2013;33:2121-9.

100.Si H, Wang J, Meininger CJ, et al. $\mathrm{Ca}(2+)$ release-activated $\mathrm{Ca}(2+)$ channels are responsible for histamine-induced $\mathrm{Ca}(2+)$ entry, permeability increase, and interleukin synthesis in lymphatic endothelial cells. Am J Physiol Heart Circ Physiol 2020;318:H1283-H1295.

101. Regoli D and Barabe J. Pharmacology of bradykinin and related kinins. Pharmacol Rev 1980;32:1-46.

102. Aschner JL, Lum H, Fletcher PW, et al. Bradykininand thrombin-induced increases in endothelial permeability occur independently of phospholipase $\mathrm{C}$ but require protein kinase C activation. J Cell Physiol 1997;173:387-96.

103. Adamson RH, Zeng M, Adamson GN, et al. PAF- and bradykinin-induced hyperpermeability of rat venules is independent of actin-myosin contraction. Am J Physiol Heart Circ Physiol 2003;285:H406-H417.

104.Farmer SG, Burch RM, Meeker SA, et al. Evidence for a pulmonary B3 bradykinin receptor. Mol Pharmacol 1989;36: $1-8$.

105.Leeb-Lundberg LM, Kang DS, Lamb ME, et al. The human B1 bradykinin receptor exhibits high ligandindependent, constitutive activity. Roles of residues in the fourth intracellular and third transmembrane domains. J Biol Chem 2001;276:8785-92.

106. de Weerd WF, Leeb-Lundberg LM. Bradykinin sequesters B2 bradykinin receptors and the receptor-coupled Galpha subunits Galphaq and Galphai in caveolae in DDT1 MF-2 smooth muscle cells. J Biol Chem 1997;272:17858-66.

107.Predescu D, Predescu S, Malik AB. Transport of nitrated 
albumin across continuous vascular endothelium. Proc

Natl Acad Sci USA 2002;99:13932-7.

108. Sharma JN. Basic and clinical aspects of bradykinin receptor antagonists. Prog Drug Res 2014;69:1-14.

109. Yong T, Gao XP, Koizumi S, et al. Role of peptidases in bradykinin-induced increase in vascular permeability in vivo. Circ Res 1992;70:952-9.

110. Cicardi M, Banerji A, Bracho F, et al. Icatibant, a new bradykinin-receptor antagonist, in hereditary angioedema. N Engl J Med 2010;363:532-41.

111. Bartal C, Zeldetz V, Stavi V, et al. The role of icatibantthe $\mathrm{B} 2$ bradykinin receptor antagonist-in life-threatening laryngeal angioedema in the ED. Am J Emerg Med 2015;33:479.e1-3.

112. Hocking DC, Phillips PG, Ferro TJ, et al. Mechanisms of pulmonary edema induced by tumor necrosis factoralpha. Circ Res 1990;67:68-77.

113. Cho K, Adamson LK, Greenhalgh DG. Parallel selfinduction of TNF-alpha and apoptosis in the thymus of mice after burn injury. J Surg Res 2001;98:9-15.

114. Tsurumi A, Que YA, Ryan CM, et al. TNF- $\alpha /$ IL-10 Ratio Correlates with Burn Severity and May Serve as a Risk Predictor of Increased Susceptibility to Infections. Front Public Health 2016;4:216.

115. O'Halloran E, Kular J, Xu J, et al. Non-severe burn injury leads to depletion of bone volume that can be ameliorated by inhibiting TNF- $\alpha$. Burns 2015;41:558-64.

116. Spies M, Chappell VL, Dasu MR, et al. Role of TNFalpha in gut mucosal changes after severe burn. Am J Physiol Gastrointest Liver Physiol 2002;283:G703-8.

117. Maass DL, White J, Horton JW. IL-1beta and IL-6 act synergistically with TNF-alpha to alter cardiac contractile function after burn trauma. Shock 2002;18:360-6.

118.Lo SK, Everitt J, Gu J, et al. Tumor necrosis factor mediates experimental pulmonary edema by ICAM1 and CD18dependent mechanisms. J Clin Invest 1992;89:981-8.

119. Ishii Y, Lo SK, Malik AB. Neutrophil adhesion to TNF alpha-activated endothelial cells potentiates leukotriene B4 production. J Cell Physiol 1992;153:187-95.

120. Ferro T, Neumann P, Gertzberg N, et al. Protein kinase C-alpha mediates endothelial barrier dysfunction induced by TNF-alpha. Am J Physiol Lung Cell Mol Physiol 2000;278:L1107-17.

121. Kiemer AK, Weber NC, Fürst R, et al. Inhibition of p38 MAPK activation via induction of MKP-1: atrial natriuretic peptide reduces TNF-alpha-induced actin polymerization and endothelial permeability. Circ Res
2002;90:874-81.

122. Rotundo RF, Curtis TM, Shah MD, et al. TNF-alpha disruption of lung endothelial integrity: reduced integrin mediated adhesion to fibronectin. Am J Physiol Lung Cell Mol Physiol 2002;282:L316-29.

123. Tiruppathi C, Naqvi T, Sandoval R, et al. Synergistic effects of tumor necrosis factor-alpha and thrombin in increasing endothelial permeability. Am J Physiol Lung Cell Mol Physiol 2001;281:L958-68.

124. Duansak D, Somboonwong J, Patumraj S. Effects of Aloe vera on leukocyte adhesion and TNF-alpha and IL-6 levels in burn wounded rats. Clin Hemorheol Microcirc 2003;29:239-46.

125.Zhao G, Yu YM, Kaneki M, et al. Simvastatin protects hepatocytes from apoptosis by suppressing the TNF- $\alpha$ / caspase-3 signaling pathway in mice with burn injury. Ann Surg 2013;257:1129-36.

126.Zhao G, Yu YM, Kaneki M, et al. Simvastatin reduces burn injury-induced splenic apoptosis via downregulation of the TNF- $\alpha / \mathrm{NF}-\kappa \mathrm{B}$ pathway. Ann Surg 2015;261:1006-12.

127. Friedrich EE, Washburn NR. Transport patterns of antiTNF- $\alpha$ in burn wounds: Therapeutic implications of hyaluronic acid conjugation. Biomaterials 2017;114:10-22 .

128. Youn YK, LaLonde C, Demling R.The role of mediators in the response to thermal injury. World J Surg 1992;16:30-6.

129. Lum H, Barr DA, Shaffer JR, et al. Reoxygenation of endothelial cells increases permeability by oxidantdependent mechanisms. Circ Res 1992;70:991-8.

130. Chiba Y, Ishii Y, Kitamura S, et al. Activation of rho is involved in the mechanism of hydrogen-peroxide-induced lung edema in isolated perfused rabbit lung. Microvasc Res 2001;62:164-71.

131.Liu Y, Shaw SK, Ma S, et al. Regulation of leukocyte transmigration: cell surface interactions and signaling events. J Immunol 2004;172:7-13.

132. Rao RM, Yang L, Garcia-Cardena G, et al. Endothelialdependent mechanisms of leukocyte recruitment to the vascular wall. Circ Res 2007;101:234-47.

133. Block ER. Hydrogen peroxide alters the physical state and function of the plasma membrane of pulmonary artery endothelial cells.J Cell Physiol 1991;146:362-9.

134. Sumagin R, Lomakina E, Sarelius IH. Leukocyteendothelial cell interactions are linked to vascular permeability via ICAM-1-mediated signaling. Am J Physiol Heart Circ Physiol 2008;295:H969-H977.

135. Usatyuk PV, Fomin VP, Shi S, et al. Role of Ca2+ in 
diperoxovanadate-induced cytoskeletal remodeling and endothelial cell barrier function. Am J Physiol Lung Cell Mol Physiol 2003;285:L1006-17.

136. Rehou S, Shahrokhi S, Natanson R, et al. Antioxidant and Trace Element Supplementation Reduce the Inflammatory Response in Critically Ill Burn Patients. J Burn Care Res 2018;39:1-9.

137. Horton JW. Free radicals and lipid peroxidation mediated injury in burn trauma: the role of antioxidant therapy. Toxicology 2003;189:75-88.

138. Ghlissi Z, Kallel R, Sila A, et al. Globularia alypum methanolic extract improves burn wound healing process and inflammation in rats and possesses antibacterial and antioxidant activities. Biomed Pharmacother 2016;84:1488-95.

139. Carter EA, Bonab AA, Goverman J, et al. Evaluation of the antioxidant peptide SS31 for treatment of burn-induced insulin resistance. Int J Mol Med 2011;28:589-94.

140.Ben Slima S, Trabelsi I, Ktari N, et al. Novel Sorghum bicolor (L.) seed polysaccharide structure, hemolytic and antioxidant activities, and laser burn wound healing effect. Int J Biol Macromol 2019;132:87-96.

141. Cohen J. The immunopathogenesis of sepsis. Nature 2002;420:885-91.

142. Gao X, Xu N, Sekosan M, et al. Differential role of CD18 integrins in mediating lung neutrophil sequestration and increased microvascular permeability induced by Escherichia coli in mice. J Immunol 2001;167:2895-901.

143. Hirano S, Rees RS, Yancy SL, et al. Endothelial barrier dysfunction caused by LPS correlates with phosphorylation of HSP27 in vivo. Cell Biol Toxicol 2004;20:1-14.

144. Essler M, Staddon JM, Weber PC, et al. Cyclic AMP blocks bacterial lipopolysaccharide-induced myosin light chain phosphorylation in endothelial cells through inhibition of Rho/Rho kinase signaling. J Immunol 2000;164:6543-9.

145. Bannerman DD, Goldblum SE. Endotoxin induces endothelial barrier dysfunction through protein tyrosine phosphorylation. Am J Physiol 1997;273:L217-26.

146. Goldblum SE, Ding X, Brann TW, et al. Bacterial lipopolysaccharide induces actin reorganization, intercellular gap formation, and endothelial barrier dysfunction in pulmonary vascular endothelial cells: concurrent F-actin depolymerization and new actin synthesis. J Cell Physiol 1993;157:13-23.

147. Walton KA, Cole AL, Yeh M, et al. Specific phospholipid oxidation products inhibit ligand activation of tolllike receptors 4 and 2. Arterioscler Thromb Vasc Biol
2003;23:1197-203.

148. Peng X, Hassoun PM, Sammani S, et al. Protective effects of sphingosine 1-phosphate in murine endotoxin-induced inflammatory lung injury. Am J Respir Crit Care Med 2004;169:1245-51.

149. Infanger M, Schmidt O, Kossmehl P, et al. Vascular endothelial growth factor serum level is strongly enhanced after burn injury and correlated with local and general tissue edema. Burns 2004;30:305-11.

150. Ferrara N, Davis-Smyth T. The biology of vascular endothelial growth factor. Endocr Rev 1997;18:4-25.

151.Ferrara N. Vascular endothelial growth factor: molecular and biological aspects. Curr Top Microbiol Immunol 1999;237:1-30.

152. Bates DO, Harper SJ. Regulation of vascular permeability by vascular endothelial growth factors. Vascul Pharmacol 2002;39:225-37.

153.Zachary I, Gliki G. Signaling transduction mechanisms mediating biological actions of the vascular endothelial growth factor family. Cardiovasc Res 2001;49:568-81.

154. Gomez Perdiguero E, Liabotis-Fontugne A, Durand M, et al. ANGPTL4- $\alpha v \beta 3$ interaction counteracts hypoxiainduced vascular permeability by modulating Src signalling downstream of vascular endothelial growth factor receptor 2. J Pathol 2016;240:461-71.

155.Angulo J, Peiró C, Romacho T, et al. Inhibition of vascular endothelial growth factor (VEGF)-induced endothelial proliferation, arterial relaxation, vascular permeability and angiogenesis by dobesilate. Eur J Pharmacol 2011;667:153-9.

156. Rodrigues GA, Mason M, Christie LA, et al. Functional Characterization of Abicipar-Pegol, an Anti-VEGF DARPin Therapeutic That Potently Inhibits Angiogenesis and Vascular Permeability. Invest Ophthalmol Vis Sci 2018;59:5836-46.

157. Ueyama M, Yamamoto I, Sawada Y. Disseminated intravascular coagulation in the early stage after severe burn: the role of excessive thrombin generation. Nihon Geka Gakkai Zasshi 1991;92:907-12.

158. Grand RJ, Turnell AS, Grabham PW. Cellular consequences of thrombin-receptor activation. Biochem J 1996;313:353-68.

159.Esmon CT. Interactions between the innate immune and blood coagulation systems. Trends Immunol 2004;25:536-42.

160. Malik AB, Lo SK. Thrombin-endothelial interactions: role in lung vascular permeability. Mol Aspects Med 1985;8:515-54. 
161. Vogel SM, Gao X, Mehta D, et al. Abrogation of thrombin-induced increase in pulmonary microvascular permeability in PAR-1 knockout mice. Physiol Genomics 2000;4:137-45.

162. Kanai T, Ishiwata T, Kobayashi T, et al. UTI, a urinary trypsin inhibitor, for the initial treatment of patients with Kawasaki disease: a retrospective study. Circulation 2011;124:2822-8.

163. Umeadi C, Kandeel F, Al-Abdullah IH. UTI is a novel protease inhibitor and neutral protease activator. Transplant Proc 2008;40:387-9.

164. Wang FY, Fang B, Qiang XH, et al. The Efficacy and Immunomodulatory Effects of UTI and Thymosin $\alpha 1$ for Sepsis: A Systematic Review and Meta-Analysis. Biomed Res Int 2016;2016:9508493.

165.Yu L, Luo Q, Fang H. Mechanism of UTI protection against lung injury caused by lower limb ischemiareperfusion. Panminerva Med 2014;56:49-55.

166. Liu W, Pang G, Wang S, et al. Protective effect of UTI on severe pulmonary infection under immunosuppression and its molecular mechanism. Exp Ther Med 2017;14:3583-8.

167. Samarin SN, Ivanov AI, Flatau G, et al. Rho/Rhoassociated kinase-II signaling mediates disassembly of epithelial apical junctions. Mol Biol Cell 2007;18:3429-39.

168. Wei F, Liu S, Luo L, et al. Anti-inflammatory mechanism of UTI: Inhibiting the hyperpermeability of vascular endothelial cells induced by TNF- $\alpha$ via the RhoA/ROCK signal pathway. Int Immunopharmacol 2017;46:220-7.

Cite this article as: Chi Y, Liu X, Chai J. A narrative review of changes in microvascular permeability after burn. Ann Transl Med 2021;9(8):719. doi: 10.21037/atm-21-1267
169.Li D, Ji H, Zhao B, et al. Therapeutic effect of UTI on pulmonary fibrosis via downregulation of TGF- $\beta 1$, TNF- $\alpha$ and NF-кB. Mol Med Rep 2018;17:1717-23.

170. Yang ZH, Lu YJ, Gu KP, et al. Effect of UTI on myocardial ischemia-reperfusion injury through JNK and P38 MAPK signaling pathways. Eur Rev Med Pharmacol Sci 2019;23:8658-64.

171.Fang M, Zhong WH, Song WL, et al. UTI Ameliorates Pulmonary Capillary Endothelial Permeability Induced by Sepsis Through Protection of Tight Junctions via Inhibition of TNF- $\alpha$ and Related Pathways. Front Pharmacol 2018;9:823.

172.Li G, Li T, Li Y, et al. UTI inhibits oxidant-induced endothelial hyperpermeability and apoptotic signaling. Int J Clin Exp Pathol 2014;7:7342-50.

173.Luo HM, Du MH, Lin ZL, et al. UTI suppresses burn-induced lipid peroxidation and reduces fluid requirements in a Swine model. Oxid Med Cell Longev 2013;2013:904370.

174.Itagaki K, Yun JK, Hengst JA, et al. Sphingosine 1-phosphate has dual functions in the regulation of endothelial cell permeability and $\mathrm{Ca} 2+$ metabolism. J Pharmacol Exp Ther 2007;323:186-91.

175. Gingras D, Lamy S, Béliveau R. Tyrosine phosphorylation of the vascular endothelial-growth-factor receptor-2 (VEGFR-2) is modulated by Rho proteins. Biochem J 2000;348:273-80.

(English Language Editor: J. Gray) 